\title{
A Study of Quality Improvement of Natural Rubber Products by Drying Methods
}

\author{
Felix Osarumhense Aguele1, Justice Agbonayinma Idiaghe², \\ Tochukwu Uzoma Apugo-Nwosu 1 \\ ${ }^{1}$ Department of Chemical Engineering Technology, Michael Okpara University of Agriculture, Umudike, Nigeria \\ ${ }^{2}$ Department of Polymer Technology, Auchi Polytechnic, Auchi, Nigeria \\ Email: aguelefelix@yahoo.com
}

Received 19 March 2014; accepted 9 November 2015; published 13 November 2015

Copyright (C) 2015 by authors and Scientific Research Publishing Inc.

This work is licensed under the Creative Commons Attribution International License (CC BY). http://creativecommons.org/licenses/by/4.0/

(c) (i) Open Access

\section{Abstract}

This experimental study was carried out to verify the quality enhancement of Natural Rubber Products by drying methods and ascertain to what extent the different methods of drying affected the properties exhibited. During this study, samples of natural rubber coagulum were obtained and a sample each was subjected to one of these three methods of drying: air, smoke and oven. The qualities of the dried rubber samples from the three methods of drying were then investigated. The criterion adopted for quality in this study was Plasticity Retention Index (PRI), which gave insight of the oxidative resistance of natural rubber, a measure of quality. The plasticity retention index was tested by using the Wallace plastimeter. The PRI values were calculated for the samples. Results obtained from this study showed that the qualities of natural rubber samples were actually influenced to different measurable extents depending on drying methods, as exhibited in the PRI levels. The results further gave basis for our conclusions that the smoke dried rubber samples had the poorest qualities, having the lowest values of PRI; followed by the oven and air dried samples respectively in terms of their PRI presented the best qualities, the highest PRI values.

\section{Keywords}

Drying, Natural Rubber, PRI, Degradation and Ozonolysis

\section{Introduction}

The rubber industry is a very vital one, feeding many other industries with their outputs. Among the beneficiary industries are the automobile, foot wear and construction industries, just to mention a few. These examples of dependent industries bring to fore the very important nature of the rubber industry. 
Rubber industry relies highly on a great deal of inputs from the natural rubber (NR) source, being one of the most used rubber material owing to its unique inherent properties [1]-[5]. This position is still being maintained even with the advent of numerous types of rubber from synthetic sources and has been made possible because of some premium properties inherent on natural rubber. For instance, natural rubber is known to have a very high green strength, ranging between $15 \mathrm{MN} \cdot \mathrm{m}^{-2}$ and $20 \mathrm{MN} \cdot \mathrm{m}^{-2}$ in its unfilled state [1]. This unique strength relies on the ability of natural rubber to crystallise on elongation, giving high tensile strength in the direction of elongation [2]. That behaviour produces a superior form of reinforcement as it limits movement between neighbouring molecular chains and leads to increase in hysteresis and ultimate strength [3]. This property is usefully harnessed in the application of natural rubber in some areas.

For the continuous existence of natural rubber in the raw materials market feeding the rubber industry, it requires that certain minimum standards of qualities must be maintained. In search of means of controlling the quality of this material as to keep within standard, we need good understanding of some fundamental parameters which have effects on the properties of rubber. This is derived from detailed studies of the parameter of interest. The drying method (s) employed to obtain the dry rubber that is afterwards processed in the industry is one of such phenomenon with the potentials to affect the properties of the final products [6]. As the drying methods vary, it is expected that the qualities of the subsequent rubber products may vary too since drying methods affect the consistency of the rubber, which is later exhibited in the products properties.

Selecting the drying method (s) is a technical issue; stringent attention is given to temperature levels because excess or insufficient temperature can result in defective products [6] [7].

Generally polymers, with exception of fluoropolymers are susceptible to oxidative degradation [1] [8]. Exposure to increased temperatures and ultra violet (UV) radiations facilitates this type of degradation, which is a free radical process initiated by thermal or photolytic cleavage of bonds [8].

When natural rubber is subjected to attack from strong oxidising agent, oxidative degradation occurs. The raw natural rubber in its unprocessed and unvulcanised state is highly vulnerable to oxidation and ozonolysis. This vulnerability is attributed to the presence of double bonds (unsaturation sites) in its main backbone chain structure [1] [4] [8]-[10].

Natural rubber can be oxidised directly by oxygen or indirectly by oxidising agents like metals and other oxygen donors. The oxidative degradation alters the original structure of the rubber due to reaction with oxygen at the sites of unsaturation (double bonds) in presence of heat. Ozonolysis leads to the formation of cyclic ozonides and both the oxidative degradation and ozonolysis eventually result to chain scission [8]. Degradation causes increase in hardness, brittleness, reduction of tensile strength and loss of colour. Symptoms of this form of degradation include hard thin films formed on the surface of products, which can crack easily on slight flexing. From the cracks initiated, tear can start and next eventually cause mechanical failure of the products [1] [8] [11] [12]. See Figure 1. Standards for evaluation of natural rubber quality make reference to fungi growth, moisture content, colour and bubbles for visual observation and rating [6] [7].

Plasticity Retention Index (PRI) is one parameter determined in accordance with ISO recommendation for grading natural rubber. Normally, plasticity retention tests are done on raw rubber even before mastication, compounding and the subsequent product formation. Its values give useful insights to certain performance aspects of rubber during mastication, compounding as well as ageing properties of the subsequent rubber products [13]. PRI was actually used in this study as a basis for estimating the quality of natural rubber. Plasticity Retention Index (PRI) is defined as the measure of resistance of a polymer material to oxidative degradation. Since oxidative behaviour of a natural rubber sample will largely affect its properties/qualities during processing and subsequent field application, it is expected that evaluation of its PRI will give a reasonable insight into properties that would be exhibited by the finished product of a given rubber sample. Three methods of drying were experimented during this study-air drying, smoke drying and oven drying.

\section{Experimental}

\section{Materials}

Natural rubber latex was used during this study. Concentrated natural rubber latex was obtained from Rubber Research Institute, Iyanomo, Benin, Nigeria. Analytical grade of Formic acid was obtained from Rovet Chemicals, Benin and used as received. Equipment used included Two-roll mill, Wallace Plastimeter and standard Punch. 


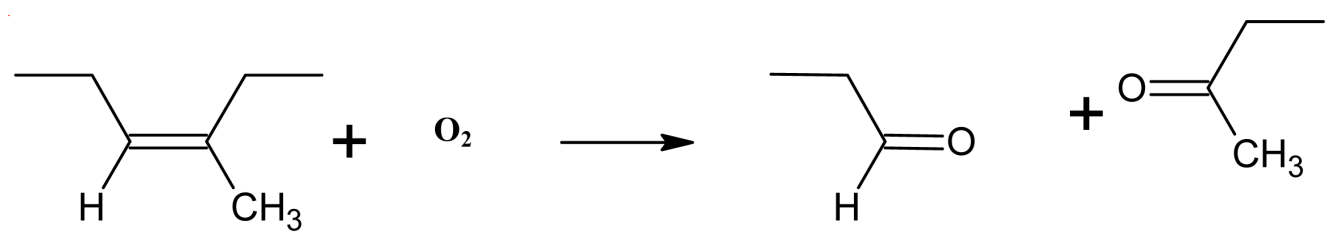

(b) Chain scission from photo oxidation of NR

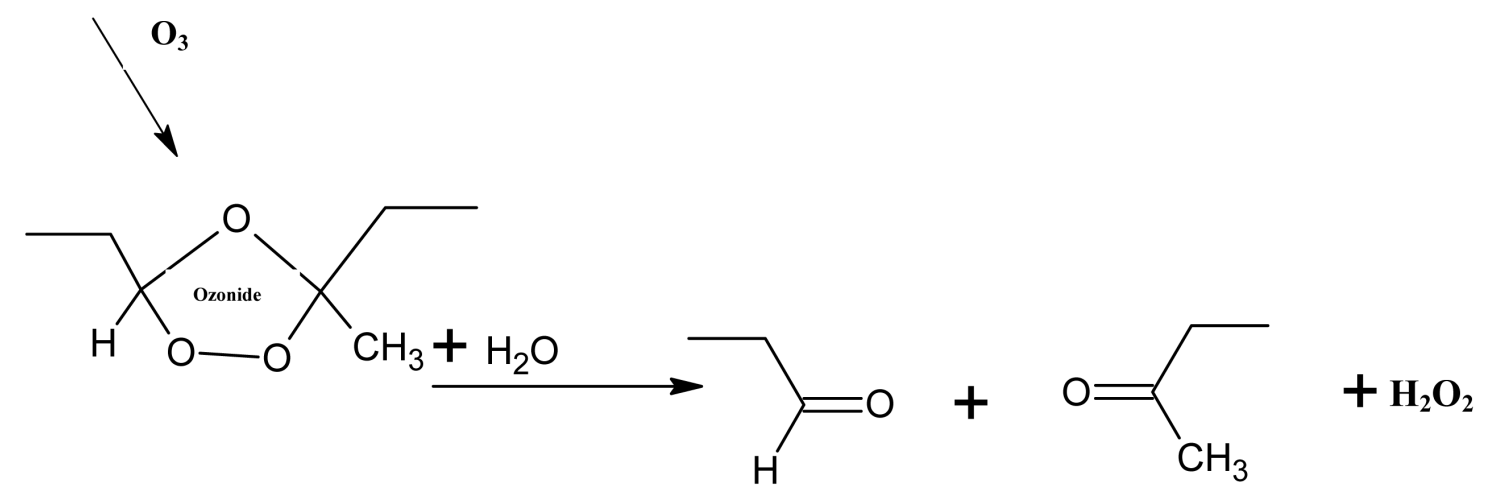

(a) Formation of cyclic ozonide and subsequent chain scission from ozone attack (ozonolysis) of NR

Figure 1. Ozonolysis and photo oxidative degradation of natural rubber.

\section{Method}

\subsection{Preparation of Materials}

Coagulation: The natural rubber latex was coagulated using 10\% formic acid [1] [5] [14] [15]. The coagulum was sheeted using a two-roll mill and the sheets were made ready for drying. The drying was done via the three methods mentioned earlier as adopted and experimented for the purpose of this study:

- Air drying,

- Oven drying and

- Smoke drying methods.

From the dried sheets, test samples were taken for analysis.

Air Drying: Air drying of the rubber sheets was done by placing samples in a well ventilated room, shaded from direct sun light. It was necessary to keep the rubber sheets from direct sun to avoid the possible negative degradative effects of the sun [7]. During this process, the rubber sheets were hung on racks under shade. The experiments were conducted during the months of December and February (hamattan period in Nigeria), when the prevailing humidity is known to be lowest, within the range of $10 \%$ to $12 \%$ and wind velocity high [16]. In this condition, the samples were dried at ambient temperatures ranging from $27^{\circ} \mathrm{C}-33^{\circ} \mathrm{C}$. This condition was maintained for six days (144 hrs), after which the sheets were considered to have sufficiently dried [9] [10].

Smoke Drying: In the case of smoke drying, the samples were hung over a fire place for three days i.e. seventy-two hours (72 hrs) under a temperature condition ranging from $38^{\circ} \mathrm{C}-45^{\circ} \mathrm{C}$ in a smoking room. In this condition, the samples were treated by both the heat and smoke emanating from the fire, thereby drying the samples faster. More so, the smoke is expected to act as preservative, preventing the growth of mould on the rubber [6] [7].

Oven Drying: During oven drying operation, the samples were placed in an oven maintained at a temperature of $55^{\circ} \mathrm{C}$. During this process, the temperature was carefully managed, to avoid excessive heating, which can cause burning and/or too low temperature, which would require too long period to produce sufficiently dried and matured sheets or may even allow fungi growth on samples [13]. The drying was done for half day (12 hrs), after which the samples were considered dried enough for further processing and analyses.

Generally, the moisture content of the sheets was used as a basis to determine the drying period for each case of drying during this study. The wet sheets had moisture content ranging between $42 \%$ and $50 \%$ before drying. The samples were considered to have sufficiently dried when their moisture contents dropped to a range of $0.8 \%$ - 
$1.5 \%$ and the time interval it took to get to that level of dryness was taken as the drying time. Table 1 presents the moisture contents of the rubber samples before and after drying.

\subsection{Tests}

The tests of plasticity retention index were done in standard methods [17]. The procedure as explained below was used.

Preparation of test pieces: Each set of sample sheets, which had been dried separately using one of the three methods as described above, were masticated by passing it through the nip of the two-roll mill repeatedly for six times. This operation helped to homogenise and soften the rubber so that it could be sheeted out easily. The nip was adjusted to obtain sheets of approximately $2 \mathrm{~mm}$ in thickness. Test samples, six pieces (pellets) in each case were cut from the various homogenised sheets of the dried (air-dried, smoke-dried and oven dried) rubber using the Wallace punch. The test pieces were divided into two sets of three; one set each for determination of plasticity before and after accelerated ageing. Tests were done using the Wallace parallel plate plastimeter [17].

Ageing of the test pieces: Accelerated ageing of the samples was done by inserting one set of test pieces in an oven maintained at a temperature of $140^{\circ} \mathrm{C}$ for 30 minutes, after which their rapid plasticity were obtained.

Plasticity tests: The rapid plasticity of the samples were determined by sandwiching each test piece between two pieces of cigarette foil and compressing between two parallel platens of the plastimeter to a fixed thickness of $1.00 \mathrm{~mm}$. After being held in this position for fifteen seconds $(15 \mathrm{~s})$ to reach equilibrium of temperature, it was then subjected to a compressive force of $10.0 \mathrm{kgf}$ for thirty seconds. Its thickness at the end of this period was taken as a measure of rapid plasticity. Three readings were taken, one from each sample, from which average of readings was calculated for each sample. The values obtained from the tests were used to compute for the Plasticity Retention Index as given below:

$$
P R I=\frac{P_{30}}{P_{0}} \times 100 \%
$$

where:

$P_{0}=$ Average plastimeter reading for the unaged rubber;

$P_{30}=$ Average plastimeter reading after accelerated ageing of rubber.

\section{Results}

\subsection{Discussion}

The drying rate (in other word, drying time), does not really affect the property of the product, but the extent of drying, which is exhibited as the moisture content of the dried rubber. That influenced our reason to allow the drying time to vary during the experiment while the moisture content of the dried rubber samples was controlled within a range of $0.8 \%-1.5 \%$ (see Table 1 ).

Generally, the results obtained for PRI were above $50 \%$, which may be seen as good values. The results indicated highest values of PRI for the Air-dried samples, followed closely by those of oven-dried samples, while those of the smoke-dried samples were the least. This result indicated that the different conditions of drying adopted for rubber actually have significant effects on the quality of products as measured by the rubber's Plasticity Retention Index (PRI) in this study. The result from our study showed that the PRI, which was used as a measure of quality, is influenced to different extents by the different drying methods explored during the study. From the results presented as shown in Table 2 and the subsequent charts plotted from data obtained (Figure 2), the PRI values were found to be $83.33 \%, 57.14 \%$ and $80 \%$, for the air-dried, smoke-dried and oven-dried samples respectively.

High values of PRI indicate high resistance to oxidative degradation and ozonolysis. This means that the material is able to retain its good properties over sometime, which translates into high quality of the subsequent

Table 1. Moisture content of the rubber samples before and after drying.

\begin{tabular}{cc} 
Parameter & Value \\
\hline Initial moisture content sheets before drying & $42 \%-50 \%$ \\
Moisture content of sheets after drying & $0.8 \%-1.5 \%$ \\
\hline
\end{tabular}


Table 2. Results obtained from tests of samples dried by the three methods.

\begin{tabular}{|c|c|c|c|c|c|}
\hline $\begin{array}{l}\text { Drying } \\
\text { Conditions }\end{array}$ & Drying Period & Temperature $\left({ }^{\circ} \mathrm{C}\right)$ & $\begin{array}{l}\text { Average Plasticity } \\
\text { before Ageing }\left(\mathrm{P}_{0}\right)\end{array}$ & $\begin{array}{l}\text { Average Plasticity } \\
\text { after Ageing }\left(\mathbf{P}_{30}\right)\end{array}$ & PRI (\%) \\
\hline Air & 6 days (144 hrs) & $27-33$ & 36 & 30 & 83.33 \\
\hline Smoke & 3 days (72 hrs) & $38-45$ & 14 & 8 & 57.14 \\
\hline Oven & 1/2 day (12 hrs) & 55 & 40 & 32 & 80 \\
\hline
\end{tabular}

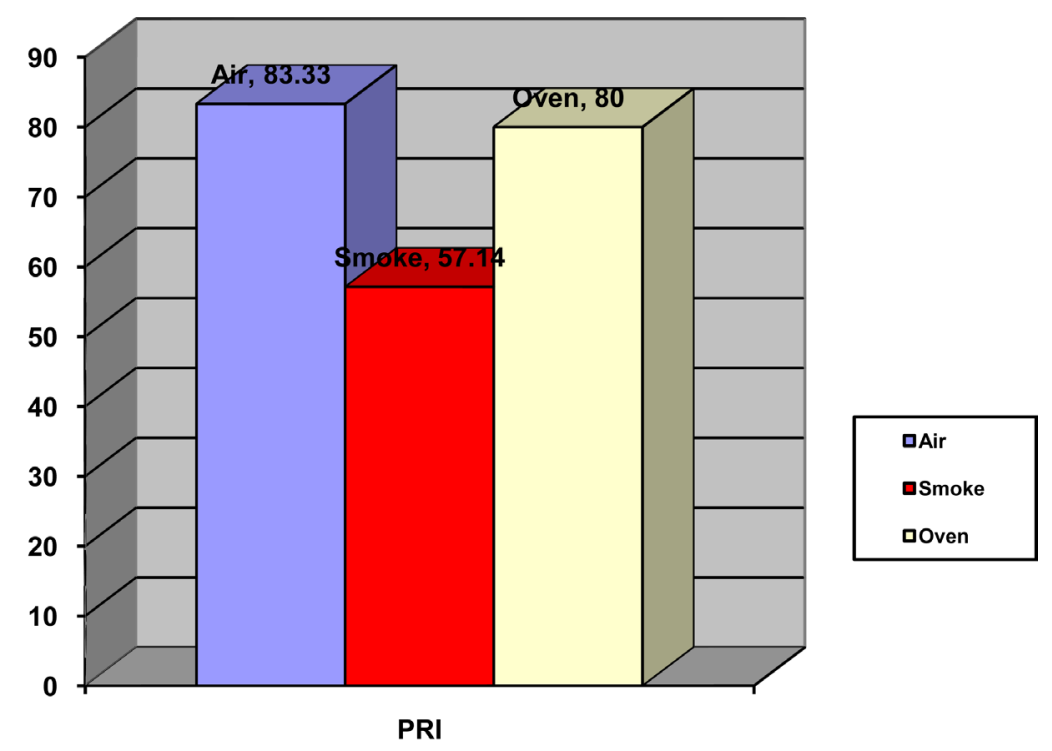

Figure 2. Charts showing the PRI for rubber samples dried by different methods.

rubber products.

During our study, PRI was used as a basis for quality measurement. The samples which were dried by air and oven presented good and acceptable values of PRI, since these values were above $60 \%$, which is the required standard minimum plasticity retention index for rubber. This is an indication of good quality. But the smokedrying method yielded low quality samples, since the PRI obtained (57.14\%) was actually below the acceptable minimum standard of $60 \%$. This showed air drying method to be the best alternative among the three methods experimented. This assertion was drawn from the fact that the air-dried samples had highest PRI value of 83.33\%, closely followed by oven-dried, samples with PRI value of $80.00 \%$ and smoke-dried samples were at the rear, having PRI of 57.14\%. Though the basis for this low value of PRI exhibited by the smoke-dried samples could not be ascertained, it was sufficient to say that smoke drying gave samples of poor quality in comparison with the other two methods (air drying and oven drying) that we experimented. Generally, it is expected that smoke-dried samples would exhibit better properties since samples received extra treatment from smoke. Perhaps there were excessive inclusions of particles from smoke treatment leading to the poor behaviour observed during the study.

A close look at our results we observed that though the different drying conditions experimented were at different temperature conditions, the results (i.e. PRI values) did not increase or fall in values directly relative to temperature changes. On this ground, we deduced from this experimental study that drying temperatures may not be the only significant factor that can affect quality of natural rubber products. For instance, drying rate is significantly affected by the drying temperature, prevailing relative humidity during experiment and wind speed. As earlier stated, the drying rate does not really affect subsequent processing of rubber products.

\subsection{Conclusions}

The experimental study carried out as presented in this paper was inclined to investigate how different conditions of drying of natural rubber materials would affect the properties exhibited by the rubber during subsequent 
processing and hence the qualities during field life of final products. In the study, PRI was used as the yard stick for the measurement of quality.

From the results obtained, it was found that:

- The drying methods adopted actually had measurable influence on the qualities of natural rubber samples as expected.

- Drying temperatures might not be the only significant factor that could affect the quality of natural rubber products.

- The three methods of drying experimented affected qualities of rubber samples to different extents.

- The air dried samples exhibited the highest value of PRI of the three drying methods studied, followed by the oven dried sample and the smoke dried samples presented the least values of PRI.

This is an indication that air drying of natural rubber samples would give a reasonably good result during processing and service life of products. This experimental study further showed that air dried samples exhibited better properties than the samples obtained via oven and smoke drying. This means that among the three methods of drying experimented, air drying of samples has potentials to impart the best quality improvement on the properties of the subsequent products followed by oven drying, and smoke drying respectively.

On the basis of results obtained from this experimental study, it would be recommended that air drying of coagulated natural rubber samples should be done in preference to the other two alternatives and should be adopted anywhere possible as the drying method of choice.

\section{References}

[1] Asore, E.J. (2000) Introduction to Rubber Technology. Joseg Books, Benin.

[2] Bhantnagar, M.S. (2004) A Textbook of Polymers: Chemistry and Technology of Polymers; (Processing and Applications), Vol. II. S Chand New Delhi.

[3] Cain, M.E. (1974) Engineering Design with Natural Rubber. Malaysian Rubber Producers' Research Association, Hertford.

[4] Billmeyer, F.W. (1970) A Textbook of Polymer Science. John Wiley and Sons, New York.

[5] Goetz, W.P. Encyclopaedia. Britannica (UK) Ltd., London.

[6] Ediati, R. and Jajang, R.F. (2010) Mathematical Model of Smoking Time Temperature Effect on Ribbed Smoked Sheets Quality. International Journal of Mathematical, Computational, Physical, Electrical and Computer Engineering, 4, 282-286.

[7] Siriwardena, S., Perera, K.K.C.K., Siriwardena, T.A.S. and Ranasinghe, J.A.D.S.S. (2010) A Small Scale Open Sun Dryer for Sheet Rubber Drying. Bulletin of the Rubber Research Institute of Sri Lanka, 51, 42-48.

[8] Fried, J.R. (2005) Polymer Science and Technology. Prentice Hall, India.

[9] Phriyawirut, M., Limwongwatthananan, T., Kaemram, S. and Wiengkaew, S. (2013) Natural Rubber/Fluoro Elastomer Blends: Effect of Third Component on Cure Characteristics, Morphology, Mechaical Properties and Automotive Fuel Swelling. Open Journal of Polymer Chemistry, 3, 79-85. http://dx.doi.org/10.4236/ojpchem.2013.34014

[10] Ranby, B. (1993) Basic Reactions in the Photodegradation of Some Important Polymers. Journal of Macromolecular Science, Part A: Pure and Applied Chemistry, 30, 583-594.

[11] Blow, C.M. (1971) Rubber Technology and Manufacture. Butterworth, London.

[12] Kumar, A. and Gupta, R.K. (1998) Fundamentals of Polymers. International Edition. McGraw Hill, Singapore.

[13] Nwanorh, K.O. and Enyiegbulam, M.E. (1998) Enhancement of Resistance to Oxidative Degradation of Natural Rubber through Latex Degradation. Chinese Journal of Polymer Science, 16, 170-175.

[14] Katchy, E.M. (2000) Introduction to Rubber Technology. El’Demark, Enugu.

[15] Calvert, K.O., Ed. (1982) Introduction to Polymer Lattices and their Applications. Applied Science Publishers, London.

[16] Minka, N.S. and Ayo, J.O. (2013) Influence of Cold-Dry (Hammattan) Season on Colonic Temperature and the Development of Pulmonary Hypertension in Broiler Chickens and the Modulating Effect of Ascorbic Acid. Journal of Open Access Animal Physiology, 6, 1-11.

[17] ASTM D3194-04 (2009) Standard Test Methods for Natural Rubber_Plasticity Retention Index (PRI). 